\title{
Wittgenstein y el pensamiento de América Latina
}

\author{
Carlos Pereda \\ Instituto de Investigaciones Filosóficas \\ Universidad Nacional Autónoma de México \\ jcarlos@filosoficas.unam.mx
}

Una vez superada cierta comprensible sorpresa, el título «Wittgenstein y el pensamiento de América Latina» invita a indagar siguiendo, entre otras, dos perspectivas de trabajo. La primera conduce a rastrear la recepción del pensamiento de Wittgenstein en la filosofía o, tal vez, más en general, en la cultura de América Latina. De esta manera, esa perspectiva nos exige redactar un capítulo de la historia de las ideas en esta región, recogiendo y, tal vez, evaluando los diferentes tipos de presencia de su pensamiento. En este ensayo quiero explorar una segunda perspectiva, más reflexiva que descriptiva e histórica, y que parte de la siguiente inquietud: ¿qué nos puede enseñar Wittgenstein a quienes trabajamos en la filosofía en América Latina?

Ante todo, propongo contrastar la lección material con la lección formal que es capaz de darnos un pensador. Por «lección material» entiendo aquellas enseñanzas que se originan en cómo un pensador plantea, trabaja, soluciona o disuelve con buenas razones cierto número de problemas o pseudoproblemas. En el caso de Wittgenstein, procuraríamos apren- 
der su lección material si nos detuviésemos a estudiar, por ejemplo, cómo en el Tractatus logico-philosophicus se discute un concepto de mundo, en tanto la totalidad de los hechos, no de las cosas, o su contraste entre decir y mostrar. También atenderíamos esa lección material examinando en las Investigaciones filosóficas la crítica a la concepción representacionalista, tradicional, del lenguaje, o su propuesta de repensar el significado a partir de los usos de las palabras en ciertos «juegos del lenguaje», o su disolución de la tentación de un lenguaje privado. También recibiríamos esa lección material si consideramos cómo su libro Sobre la certeza contribuye a desembarazarnos, a partir de un razonamiento antifundacionista, de un concepto tradicional, cartesiano, absoluto y de certeza.

Por el contrario, la lección formal de un pensador no consiste tanto en retener los aportes respecto del tratamiento de este o aquel problema, o pseudo-problema concreto, sino en aprender de algunas de sus técnicas de pensamiento más habituales. Sin embargo, quien aprende una lección formal, a la vez que procura entrenarse en un modo de proceder, en un saber práctico, en un knowing how, recoge también lo que podríamos llamar, más propiamente, una sabiduría. Por ejemplo, Wittgenstein usa varias metáforas para señalar frecuentes caminos equivocados del pensamiento. Esas metáforas no indican tanto posibles errores aislados - digamos, planteamientos o metodologías equivocadas para enfrentar cierto problema y nada más-, sino orientaciones radicalmente distorsionadas de practicar la filosofía. Según el parágrafo 103 de las Investigaciones filosóficas:

El ideal, tal como lo pensamos, está inamoviblemente fijo. No puedes salir fuera de él: siempre tienes que volver. No 
hay ningún afuera; afuera falta aire - ¿De dónde proviene esto? La idea se asienta como unas gafas ante nuestras narices y lo que miramos lo vemos a través de ellas. Nunca se nos ocurre quitárnoslas ${ }^{1}$.

En este pasaje, Wittgenstein no sugiere cambiar cierto par de lentes por otro (por ejemplo, el par que él nos recetase), sino quitarnos los lentes para atender «el afuera»: ese afuera al cual nuestros prejuicios y fantasías nos hacen creer que falta el aire. ¿En qué consiste «el afuera»? Por lo pronto, en la variada multitud de sucesos que nos rodean y que también hacemos nosotros, en nuestras acciones, pero sobre todo en los muchos fragmentos del mundo que no se pueden percibir a través de nuestros lentes. Por eso, se trata de renunciar a esos lentes y, ante todo, de ejercitarse en el difícil mirar como las cosas son, no como nuestros prejuicios y fantasías querrían que fuesen. Sobre todo, hay que procurar atender con justeza, rehuyendo las tentaciones de la inmovilidad a que nos seduce cualquier perspectiva ya adoptada. En particular hay que cuidarse de las perspectivas que se afilian a ideales adictivos: esos que nos prometen caminos fáciles y maravillas engañosas.

En este sentido, téngase en cuenta que, no pocas veces, los errores particulares son productos de esas adicciones de observar y razonar sólo en una dirección. Por eso, a menudo nos encontramos en el razonamiento frente a vicios persistentes que, como cualquier vicio que se arraiga, cuesta mucho trabajo desprenderse.

${ }^{1}$ Todas las notas corresponden a Wittgenstein 1986 (a veces modifico ligeramente la traducción). 
A partir de observaciones como estas, la siguiente pregunta casi se vuelve previsible: ¿cuáles son algunos de los vicios que distorsionan el pensamiento latinoamericano, y cómo puede Wittgenstein ayudarnos a combatirlos? Haré un esbozo de respuesta a esta sobrecargada pregunta en dos partes. Primero, brevemente reconstruyo tres vicios recurrentes de este pensamiento. Luego recojo dos o tres propuestas de Wittgenstein que podrían ayudar a debilitarlos.

Al primer vicio lo podemos llamar «fervor sucursalero». Sin duda, la tradición de filosofía en castellano ha sido muy pobre. De ahí la necesidad de, para formarse, acudir a otras tradiciones escritas en los tiempos modernos, en particular, en lengua inglesa, alemana o francesa. De esta manera, una corriente de pensamiento de algún país lejano suele deslumbrar en la juventud y luego, ya no se investiga más: se continúa el resto de la vida paralizado en la repetición de fórmulas que, poco a poco, van perdiendo su contenido. Porque, como se considera que las Casas Matrices del Pensamiento están en otra parte, se reduce la reflexión a administrar, con energía decreciente, el establecimiento - sucursal de esa empresa- en el poblado marginal que nos tocó vivir. Pensar se reduce, pues, a un asunto de administración de franquicias, por ejemplo, a administrar la franquicia «Wittgenstein»o cualquier otra. En consecuencia, a partir de cierta edad ya no se intenta pensar más, sino que, no sin arrogancia, se sustituye la reflexión por la entusiasta «lógica de las adhesiones». Simplemente uno instala cómodamente su tiendita mental y se es para toda la vida disciplinadamente - servilmente- fenomenólogo, utilitarista, lógico-positivista, analítico, 
posanalítico, posmoderno, posposmoderno, neomarxista, neoescolástico, neofrankfurtiano, neofuncionalista, partidario de las ciencias cognitivas, o lo que sea. O más bien, más sencillamente, nos apoderamos de un autor y, en el mejor de los casos, escribimos resúmenes más o menos correctos, con títulos que, con razón, de antemano sabemos que nadie va a leer, pero qué importa, porque de cualquier manera respaldarán un currículum: «La genealogía de la epistemología en $\mathrm{A} »$, «El concepto de teoría y práctica en $\mathrm{B} »$, «El fin de la metafísica en C». Después de todo, consolidar un currículum y, sobre todo, desparramar muchas notas, multitud de notas al pie en varios idiomas si es posible, protegen más que arriesgar argumentos más o menos originales.

El segundo vicio es el «afán de novedades» y reacciona en contra del primero. En lugar de amurallarse en una tradición de pensamiento, la persona está abierta, muy abierta, pero «a lo que venga». Por supuesto, la apertura de mente y la curiosidad son virtudes preciosas. No hay investigación, no hay conocimiento sin ellas. La dificultad comienza cuando la apertura de mente degenera en andar a la deriva sin el menor proyecto más o menos a largo plazo, y la curiosidad se vuelve enfermiza, una adicción sin tregua, una adicción devoradora, entre otras razones, porque es imposible de satisfacer. En las Casas Matrices del Pensamiento siempre se estarán pensando otros problemas con otras técnicas. De esta manera, lo que preocupa no es ya conocer y comprender mejor el mundo y nuestras responsabilidades en él, sino que nos agobia la moda, la arrogante «lógica de estar al día».

En contra de estas dos «lógicas», en América Latina se nos suele llamar a liberarnos y recobrar nuestra peculiar diferencia: a dejar de mirar tanto hacia fuera para apreciar un poco lo que hemos sido y somos, y lo que ha sido y es la 
circunstancia que nos rodea. Hay que descolonizarse. Hay que recobrar la memoria histórica de tanta catástrofe para poder actuar con justicia. Lástima que estas razonables exhortaciones pronto degeneren en un nuevo vicio: la arrogancia de las identidades colectivas que conforman los «entusiasmos nacionalistas» y sus consecuencias —en la academia más ridículas que perniciosas-, las «filosofías nacionales» (la «filosofía mexicana», la «filosofía boliviana», la «filosofía ecuatoriana», la «filosofía argentina»), y sus «lógicas del color auténtico».

¿Cómo podría el elaboradísimo y sutil pensar de Wittgenstein, que en apariencia, al menos, se ocupa de asuntos muy lejanos de estas miserias, contribuir al combate de tales vicios groseros, propios de la razón arrogante latinoamericana?

Recordemos que para Wittgenstein las maneras incorrectas de atender a menudo no se reducen a errores superficiales, sino que descansan en hábitos que se han enraizado profundamente. Por eso, sólo una reorientación radical de nuestras formas de vida puede liberarnos de cualquier enloquecida «lógica» de la adicción, permitiéndonos redirigir, retransformar radicalmente la atención. Pero, ¿cómo? Encontramos una respuesta en el parágrafo 108:

(Podría decirse: la mirada debe ser rotada, pero teniendo como gozne nuestras necesidades reales).

Cada uno debe aferrarse, pues, no tanto a sus ideales $-\mathrm{y}$ mucho menos a sus fantasías y a sus adicciones-como a sus 
necesidades reales. Sin embargo, como previene Wittgenstein, se trata de recuperarlas sin «dieta de ejemplos», sin unilateralidades preconcebidas: sin urgencias que corrompen la mirada, ni lealtades a herencias que aplastan. Hay que recobrar, pues, las necesidades reales de todo tipo: necesidades económicas, morales, sociales, políticas, filosóficas, científicas y estéticas. La tradición, las rutinas y, sobre todo la fatiga, nos imponen ya demasiados sobreentendidos como anteojeras, para que nosotros le agreguemos todavía firmeza, cultivándolas.

Luego de descubrir algunas de nuestras necesidades reales, el siguiente esfuerzo consiste en desprendernos, por ejemplo, de la «lógica de las adhesiones», de la «lógica de estar al día», de la «lógica del color auténtico» que embrollan y desfiguran las creencias, los deseos, las emociones, las expectativas y, por eso, nos alejan cada vez más de las «necesidades reales». De ahí que Wittgenstein recomiende que, muchas veces, para tratar con rigor un asunto haya que llevar a cabo terapias, como indica el parágrafo 255. Sin duda, a menudo:

El filósofo trata una pregunta como una enfermedad.

No obstante, debemos cuidarnos de la apresurada tendencia - tan humana- a generalizar; porque no hay algo así como «la enfermedad». Hay muchas y diversas enfermedades, cada una con sus características específicas. De manera análoga, no existe «el vicio» ni «la pseudo-lógica», sino varios y muy diferentes vicios y pseudo-lógicas, de los cuales los ejemplos propuestos eran sólo casos recurrentes.

Conviene evitar, pues, esas fantasías peligrosas que suelen expresarse, y hasta producirse, cuando usamos los artículos 
en singular. Por ejemplo, creemos que cuando solucionamos un problema o eliminamos un vicio, solucionamos todos o muchos problemas y eliminamos todos o muchos vicios $y$, además, que lo hacemos definitivamente. Pero no: cuando se soluciona un problema a menudo se soluciona sólo un problema; y cuando se elimina un vicio con frecuencia se elimina sólo un vicio. Por eso, la lucha contra los muchos y heterogéneos vicios, y las no menos pseudo-lógicas no tiene fin, como puntualiza en el parágrafo 133:

Se resuelven problemas (se eliminan dificultades), no un problema.

Entre otras razones, es necesario recordar que no disponemos de esa engañosa maravilla, «el Método» con que soñó Descartes y, con él, gran parte de la tradición. Pero cuidado con corregir un error con otro. A las metodolatrías no hay que combatirlas con metodofobias, pues como indica el parágrafo 133:

No hay un método en filosofía, si bien hay métodos, a saber, diferentes terapias.

Sin duda, eliminar vicios prácticos o teóricos, o una mezcla de ambos, como el fervor sucursalero, el afán de novedades y el entusiasmo nacionalista, no es tarea fácil, porque esos vicios se han arraigado con fuerza adictiva en algunas de nuestras formas de vida latinoamericanas (y no sólo en filosofía, sino en toda la producción de los conocimientos). Además, apenas logramos desembarazarnos de uno de esos vicios, tendemos a caer en los otros.

No obstante, y pese a que cada vez que se presentan esos vicios, destruirlos requiere de un gran esfuerzo, paradójica- 
mente, una vez que los hemos dejado atrás, descubrimos que lo perdido eran pompas de jabón: coartadas cómodas para salir del paso en el momento, pero a la larga dañinas y sin mayor consistencia; puras ilusiones que sólo enmascaraban debilidades y cobardías. Tal vez este sea un meta-aprendizaje más o menos general: comenzar a aprender es, una y otra vez, comenzar a perder fantasías inútiles, a las que, sin embargo, nos aferramos con todas las fuerzas porque las malentendemos como de vital importancia.

Así, estas fantasías inútiles nos estorban y hasta arruinan la vida. Al respecto leamos el parágrafo 118:

¿De dónde saca nuestro examen su importancia puesto que sólo parece destruir todo lo interesante, es decir, todo lo grande e importante? (En cierto modo, todos los edificios, dejando sólo pedazos de piedra y escombros). Pero son sólo castillos en el aire lo que destruimos.

Sin embargo, la colaboración que puede brindar Wittgenstein, al combate de estos vicios y pseudos-lógicas, no es sólo negativa: no se reduce a ejemplificar la puesta en obra de terapias. Contra lo que - no sin cierta insistencia- suele proclamarse en muchas lecturas de Wittgenstein, también encontramos en este pensador una tarea positiva para la filosofía. Esta puede ofrecer una clase cualitativamente especial de entendimiento: aquel que se produce cuando la reflexión no se concentra en los fragmentos de un problema, sino que, dando un paso atrás, lo ubica y nos ubica en el horizonte más incluyente de sus relaciones con otros, incluso con problemas sin aparente relación con el que estamos tratando, y hasta con las zozobras más inmediatas de la vida humana. Pues, de acuerdo al parágrafo 122: 
Una fuente principal de nuestra falta de comprensión es que no vemos abarcadoramente el uso de nuestras palabras. A nuestra gramática le falta visión abarcadora. La exposición abarcadora comunica la comprensión que consiste en «ver conexiones»[...]. El concepto de exposición abarcadora es de fundamental significación para nosotros. Designa nuestra forma de exponer, el modo en que vemos las cosas.

Para realizar esta tarea, para constantemente atar cabos, para disponer de una «visión abarcadora» de los más diversos problemas, pseudo-problemas, soluciones, disoluciones, resulta de la mayor utilidad levantar estructuras, estabilizar diversos órdenes entre las dificultades y los procesos de dar y pedir razones. Eso sí, a cada paso hay que evitar el vértigo simplificador que conduce a las peligrosísimas fantasías de las singularidades abstractas que encandilan y, por eso, no nos dejan ver adecuadamente: la obsesión por «el Método», «el Orden», «el Vicio», «el combate al Vicio». No necesitamos, pues, de «el Orden» del mundo, sino de una sensible y, por eso, cambiante pluralidad de caminos (insisto en que hay que cuidarse, pues, también, de convertir a Wittgenstein, o a Aristóteles, o a Kant, o a quien sea, en «El único Compañero de Camino», puesto que no hay ni «El Único Compañero» ni «El Camino»). Nos pueden ser útiles, pues, las más diversas maneras de ordenar la realidad, como subraya el parágrafo 132:

Queremos establecer un orden en nuestro conocimiento del uso del lenguaje: un orden para una finalidad determinada; uno de los muchos órdenes posibles; no el orden. 
O para agregar otra metáfora: podemos prescindir de «el Mapa conceptual», pero no de los muchos y diversos mapas conceptuales que requieren nuestras diversas exploraciones. En este sentido, recordemos que hay muchos tipos de mapas. Un mapa nunca se identifica con el territorio que mapea. Los mapas se generan de acuerdo con los diversos intereses, cambian de escala y estilo, comunican más o menos información. Con un buen mapa de calles es menos probable que lleguemos tarde a ese trabajo que nos ofrecen en una ciudad que desconocemos, aunque si, luego, queremos visitar sus teatros y museos, necesitaremos echar mano de otros mapas, porque el de calles nos resultará inútil. También cuando reflexionamos necesitamos formular diversos mapas conceptuales que nos permitan ver, y aprehender, los diferentes aspectos de un asunto. Indica Wittgenstein en el prólogo de las Investigaciones:

Las anotaciones filosóficas de este libro son como un conjunto de bosquejos de paisajes que han resultado de estos largos y enmarañados viajes.

Los mismos puntos, o casi los mismos, fueron continuamente tocados de nuevo desde diferentes direcciones y siempre esbozaron nuevos cuadros.

De esta manera, si quisiéramos resumir, de la mano de Wittgenstein, un comienzo de combate a los vicios coloniales y pseudo-lógicas que aquejan nuestra filosofía - y más abarcadoramente nuestra cultura, y en general, nuestras vidas - tal vez podríamos recomendar: hay que ejercitarse para atender rotando de vez en cuando la mirada, apropiándonos de las más diversas técnicas y probando, según la circunstancia y nuestros propósitos, maneras de ordenar el mundo y evaluar 
después qué pasa. Pero todo ello sin detener el movimiento, no dejándonos paralizar por ninguna autoridad - tampoco por la de Wittgenstein-. También hay que liberarse de toda consigna acerca de lo que, según los medios masivos de comunicación, o las tradiciones intelectuales, o las Academias, publicitadamente rige en el aquí y ahora: acerca de lo que se considera «lo importante aquí», «lo que hay que pensar con urgencia ahora mismo» y otros slogans, que tanto acarician y corrompen el pensamiento. De manera simple, pero no sin dificultades, cada día se trata de, sin perder el rumbo, iniciar esa ardua aventura: abrirnos con frescura y coraje al «afuera» de los muchos caminos y de los muchos compañeros y técnicas que encontremos en esos caminos, para con renovada imaginación teórica, dejarnos interpelar por unos pocos de los problemas mismos.

\section{BIBLIOGRAFÍA}

Wittgenstein, Ludwig. (1986). Investigaciones filosóficas. Trad. Alfonso García Suárez y Ulises Moulines. México: Instituto de Investigaciones Filosóficas-Universidad Nacional Autónoma de México.

\section{RESUMEN}

El autor argumenta que es posible extraer diversas lecciones formales del pensamiento de Wittgenstein, y que dichas lecciones pueden ser útiles para combatir diversos vicios que aquejan al pensamiento latinoamericano. 
Palabras clave: Wittgenstein, Latinoamérica, metodología filosófica y vicios intelectuales.

\section{ABSTRACT}

The author argues that it is possible to extract various formal lessons from Wittgenstein's thought, and that these lessons can be useful in combating various vices that afflict Latin American thought.

Keywords: Wittgenstein, Latin America, philosophical methodology and intellectual vices. 
